\title{
ARTICLE
}

\section{Development of contamination estimation method for PWR}

\author{
Tomohiro Ogata $^{a^{*}}$, Takashi Muramatsu ${ }^{\mathrm{a}}$, Koichi Yoshisako ${ }^{\mathrm{a}}$, Kenichiro Kino ${ }^{\mathrm{b}}$, Masakazu Matsuura ${ }^{\mathrm{c}}$, \\ Toshinobu Katsumi ${ }^{\mathrm{c}}$, Tetsuo Noyori ${ }^{\mathrm{c}}$ and Hirotaka Iduka ${ }^{\mathrm{d}}$

\begin{abstract}
${ }^{a}$ Mitsubishi Heavy Industries, Ltd., 1-1-1 Wadasakicho, Hyogo-ku, Kobe, Hyogo-ken, 652-8585, Japan; ${ }^{b}$ Nuclear Development Corporation, 622-12 Funaishikawa, Tokaimura, Ibaraki-ken, 319-1111, Japan; ${ }^{c}$ Kansai Electric Power Co, Inc., 13-8 Goichi, Mihama-cho, Mikata-gun, Fukui-ken, 919-1141, Japan; ${ }^{d}$ Kanden Power-Tech Corp., 1-2-1-1800 Benten, Minato-ku, Osaka, Osaka-fu, 552-0007, Japan
\end{abstract}

\begin{abstract}
Accurate estimation of radioactive inventory is essential for nuclear power plant, since it effects on nuclide screening for clearance, disposal cost, collective dose and public exposure estimation. This paper describes contamination estimation method. Authors have developed contamination estimation method for PWR primary circuit and other systems. The method is based on the assumption that only particulates in the coolant are responsible for contamination and S. K. Beal's theory of particle deposition and erosion model. There are various contamination calculation conditions and some of them, such as failed fuel fraction, are difficult to determine with plant design data and thus measured data of radioactive waste generated from the existing plant is used for estimating fission products contamination. Contamination estimation results are in good agreement with the measured data. For the application of this method to the contamination density estimation for the PWR operational waste and for decommissioning, the improvement of estimation accuracy will be required by conducting further data accumulation regarding the plant operating data and accurate plant design parameters.
\end{abstract}

\section{Keywords: contamination; residual activity; decommissioning; clearance}

\section{Introduction}

It is important to estimate radioactive inventory of nuclear power plant for new reactor licensing, decommissioning planning, cost and collective dose and public exposure estimation. Results of this estimation are also used for radioactive inventory for the nuclides screening in clearance.

Residual activity consists of induced activity and contamination activity. Induced activity estimation method is well established by using neutron transport calculation codes (DORT [1], etc...) and activation calculation codes (ORIGEN2 [2] series etc...). Due to the complexity of representing the movement of corrosion product $(\mathrm{CP})$, fission product $(\mathrm{FP})$ and actinide in the primary circuit and the other systems, the contamination estimation method is not established.

There are some contamination estimation codes, e.g. ACE-II [3], which target primary circuit other than Reactor Heat Removal System (RHRS) and Waste Disposal System (WDS) etc..

Mitsubishi Heavy Industries, ltd. (MHI) has been developing contamination estimation method to estimate residual activity of nuclear power plant at the end of the

*Corresponding author. Email: tomohiro_ogata@mhi.co.jp plant life. It treats CPs, FPs and actinides and covers Reactor Coolant System (RCS), Chemical and Control Volume System (CVCS), RHRS, Spent Fuel Purification and Cooling System (SFPCS) and other components. This paper shows estimation methodology of CPs, FPs and actinides contamination in PWR systems considering the fuel defect.

\section{Contamination estimation method}

\subsection{Assumption}

Contamination estimation conditions are assumed as follows:

- Only particulates contribute to deposition on the inner surface of the piping and components although nuclides are particulate or ionic state in the coolant.

- Source terms are activated CPs irradiated at reactor core, FPs released from fuel surface and fuel defect.

- Radioactivity of FP is determined by FP/CP activity ratio measured in the radioactive waste generated from the existing plant.

- Modeling of deposition and erosion of the 
particulate is based on S. K. Beal's [4,5] theory. With regard to components which are difficult to be applied to Beal's theory, such as a tank with accumulated fluid, contamination density is estimated by gamma ray measurement result and dose to contamination conversion factor.

\subsection{Source terms}

\subsubsection{Activated corrosion products}

CPs in the vicinity of the reactor core is activated by neutron irradiation. Source term of the activated CPs is determined by assumed metal abundance on fuel rods, neutron flux at the reactor core and average irradiation time of the operating cycle with ORIGEN2.

\subsubsection{Fission products from fuel contamination}

Fuel rods surface have manufacturing contamination of $\mathrm{UO}_{2}$ and it produces FPs by neutron irradiation at the reactor core. Source term of FPs produced by the fuel surface contamination is determined by assumed irradiation time, burn up, neutron flux at the reactor core and the regulated surface contamination value at the manufacturing of a fuel with ORIGEN2.

\subsubsection{Fission products from fuel defect}

Source term of FPs produced by the fissioning of the fuel is determined by assumed neutron flux at the reactor core, burn up and irradiation time with ORIGEN2.

\subsection{Contamination estimation model}

\subsubsection{Reactor Coolant System (RCS)}

Contamination of the components and piping in the RCS is caused by particulate radionuclides released from the reactor core. Deposition and erosion of particulate radionuclides are modeled with S. K. Beal's theory and particulate radionuclide concentration in the coolant and deposited activity are calculated by the following equations considering particulate activity balance between the fluid and wetted surface.

$\frac{d C_{i}}{d t}=\frac{S_{i} \times R_{i} \times m_{i}}{V}-\left\{\lambda_{i}+K_{d} \times \frac{S U}{V / \rho}+\frac{Q}{V}\left[1-\frac{1}{D F_{i}}\right]\right\} \times C_{i}+B_{i} \times E \times \frac{S U}{V}$

and

$\frac{d B_{i}}{d t}=\rho \times K_{d} \times C_{i}-\left(\lambda_{i}+E\right) \times B_{i}$

where,

$\mathrm{C}_{\mathrm{i}}$ : Nuclide i particulate concentration in coolant $(\mathrm{Bq} / \mathrm{g})$

$\mathrm{S}_{\mathrm{i}}$ : Source term of nuclide $\mathrm{i}(\mathrm{Bq})$

$\mathrm{R}_{\mathrm{i}}$ : Fission product escape rate coefficient (1/s)

$\mathrm{m}_{\mathrm{i}}$ : Particulate rate of nuclide $\mathrm{i}$ in reactor coolant $(-)$

$\mathrm{V}$ : Weight of reactor coolant $(\mathrm{g})$

$\lambda_{\mathrm{i}}$ : Decay constant of nuclide i $(1 / \mathrm{s})$

$\mathrm{K}_{\mathrm{d}}$ : Deposition coefficient in RCS $(\mathrm{cm} / \mathrm{s})$

SU: Wetted surface area of RCS $\left(\mathrm{cm}^{2}\right)$

$\rho:$ RCS coolant density $\left(\mathrm{g} / \mathrm{cm}^{3}\right)$

$\mathrm{Q}$ : CVCS purification flow rate $(\mathrm{g} / \mathrm{sec})$

$\mathrm{DF}_{\mathrm{i}}$ : Demineralizer isotopic decontamination factors (-)

$\mathrm{B}_{\mathrm{i}}$ : Deposited density of nuclide $\mathrm{i}\left(\mathrm{Bq} / \mathrm{cm}^{2}\right)$

E: Erosion rate constant in RCS (1/s)

\subsubsection{Chemical and Volume Control System (CVCS)}

Radioactive particle deposition mechanism in CVCS is the same as that in RCS. Rate of increase of deposited activity at downstream of the demineralizer is given mathematically by the following activity balance equation. Here, radioactive concentration in the coolant of the upstream of the demineralizer is supposed to be the same as RCS concentration.

$$
\frac{d B_{i}}{d t}=\rho \times K_{d} \times \frac{C_{i}}{D F_{i}}-\left(\lambda_{i}+E\right) \times B_{i}
$$

\subsubsection{Residual Heat Removal System (RHRS)}

RHRS is operated at the time of plant startup and shut down. Radioactive concentration in the coolant of RHRS changes because RHRS operation condition, such as $\mathrm{pH}$ and temperature, changes with time. Rate of increase of deposited activity of the RHRS is expressed as equation (4). Radioactive concentration in the coolant of RHRS is given by the measured value of the existing plant. Figure 1 shows particulate Co-60 concentration in RHRS coolant change at RHRS operation. In this study, changes of coolant activity of each nuclide are represented by change of the particulate Co-60 concentration in RHRS because it is difficult to measure other nuclides.

$$
\frac{d B_{i}}{d t}=\rho \times K_{d} \times C_{i}-\left(\lambda_{i}+E\right) \times B_{i}
$$

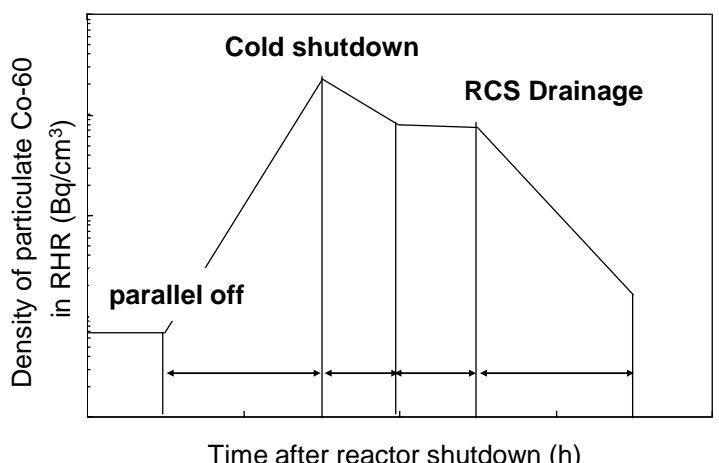

Figure 1. Co concentration change at typical RHRS operation

\subsubsection{Spent Fuel Pit Cooling System (SFPCS)}

SFPCS cools down and purifies the Spent Fuel Pit (SFP) water and reactor cavity coolant water at the time of reactor shut down.

Source term of the SFPCS is radionuclides eroded from the deposited radionuclides on the spent fuels. Equation (5) shows gradient of radioactive particulate of nuclide i concentration in SFPCS coolant. Deposited activity is given by equation (6).

$\frac{d C_{i}}{d t}=\frac{S_{0} \times m_{i}}{V_{S F P}}-C_{i}\left\{\frac{Q_{S F P}}{V_{S F P}}\left(1-\frac{1}{D F_{i}}+\eta\right)+\frac{S}{V_{S F P}} K_{d}-\lambda_{i}\right\}+B_{i} \times E \times \frac{S}{V_{S F P}}$

and

$\frac{d B_{i}}{d t}=\rho \times K_{d} \times \frac{C_{i}}{D F_{i}}-\left(\lambda_{i}+E\right) \times B_{i}$

Where,

$\mathrm{S}_{0}$ : Particulate release rate from fuel assembly $(\mathrm{Bq} / \mathrm{s})$ 
$\mathrm{V}_{\mathrm{SFP}}$ : Mass of SFPCS coolant $\left(\mathrm{cm}^{3}\right)$

$\mathrm{Q}_{\mathrm{SFP}}$ : SFPCS purification flow rate $\left(\mathrm{cm}^{3} / \mathrm{s}\right)$

$\eta$ : Filtration efficiency (-)

S: Wetted surface of SFPCS $\left(\mathrm{cm}^{2}\right)$

\subsubsection{Waste disposal system and other components}

A tank which is not operated on a continuous basis, such as spent resin storage tank (SRST) of WDS, is not always in contact with the moving fluid and there is accumulated fluid in the tank. It is difficult to apply S. K. Beal's theory to the components with accumulated fluid because S. K. Beal's theory is for the particle in the flow.

Contamination density of WDS and other components are estimated by gamma ray measurement result and dose to contamination conversion factor, which is prepared in advance. Conversion factor is calculated by point kernel code QAD-CGGP2R [6]. Nuclide composition of WDS and other components is assumed to be the same as that of RCS in this calculation.

\subsection{Fuel defect consideration}

\subsubsection{Fuel defect reflection on the source terms}

It is known that concentrations of alpha-nuclides become high in the coolant after fuel defect. Effect of the fuel defect needs to be considered. Figure 2 shows basic concept of the fuel defect effect on the coolant concentration and the source terms.

Alpha-nuclides are released by fuel defect and concentration of alpha-nuclides decreases with time due to the CVCS purification. In order to simulate change of alpha-nuclides in the coolant, alpha-nuclides/Co-60 ratio of the source term is corrected by the measured alpha-nuclides/Co-60 concentration ratio of CVCS letdown filters in the considered plant. Alpha-nuclides/Co-60 ratio of the CVCS letdown filters represents fuel defect effect in the coolant for a long term period because alpha-nuclides are released into the coolant by the fuel defect and Co-60 concentration in the coolant is almost constant regardless of the fuel defect.
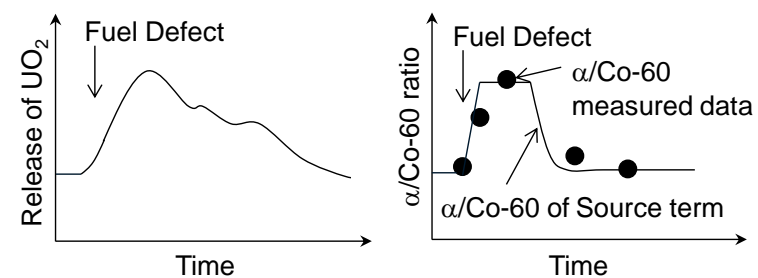

Figure 2. Modeling of source term with fuel defect

\subsubsection{Fuel defect reflection on contamination}

Reflecting the measured alpha-nuclides/Co-60 ratio of coolant filter on source term is not sufficient to estimate absolute contamination density value of FPs and actinides. Measured Cs-137/Co-60 of the radioactive waste generated from the considering plant is introduced to meet the measured FPs and actinides data (Figure 3). Contamination density of FPs is corrected by multiplying Cs-137/Co-60 ratio. Cs-137/Co-60 ratio is used for the correction because of the following three reasons: (i) Cs-137 represents $\mathrm{FP}$ and is easier to be measured than the other nuclides of FP, (ii) Co-60 represents $\mathrm{CP}$ and is easy to be measured, (iii) calculated contamination density of Co-60 is consistent with measured data.

\section{Contamination estimation}

Contamination estimation is carried out for the model plant. Table 1 and Table 2 show source term evaluation condition and contamination estimation condition, respectively.

Figure 4 shows comparison between calculated results of $\mathrm{Mn}-54 / \mathrm{Co}-60$ ratio and measured $\mathrm{Mn}-54 / \mathrm{Co}-60$ ratio of the radioactive waste generated from considered plant. And Figure 5 shows comparison of Cs-137/Co-60 ratio between calculation and measurement, and specifies that both estimated CPs and FPs concentration are in good agreement with the measured data.

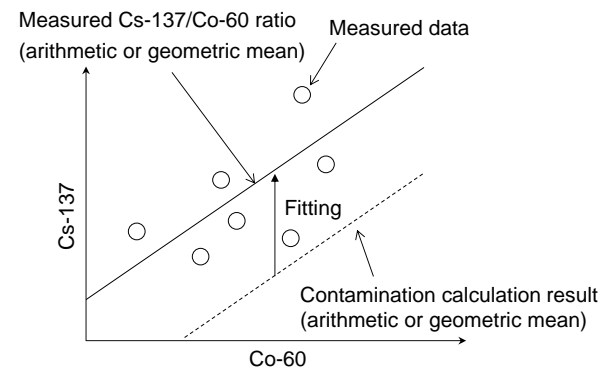

Figure 3. FPs density fitting to the measured data

Table 1. Source term estimation condition

\begin{tabular}{cll}
\hline $\begin{array}{c}\text { Source } \\
\text { term }\end{array}$ & \multicolumn{1}{c}{ Parameter } & \multicolumn{1}{c}{ Source } \\
\hline $\mathrm{CP}$ & Amount of CRUD at core & Calculated by plant data \\
& CRUD composition & SUS304 and Inconel 690 \\
& neutron flux at the core & Plant design data \\
\hline FP/ & Bun-up and specific power & Plant design data \\
actinides & Irradiation time of a cycle & 13 months operation \\
& Cooling time of a cycle & 45 days outage \\
& Fuel composition & ORNL/TM-6051 [7] \\
& U-235 enrichment & Plant design data \\
& $\mathrm{U}$ amount & Plant design data \\
& $\mathrm{UO}_{2}$ contamination at fuel surface & JEAG 4204-2009 [8] \\
\hline
\end{tabular}

Table 2. Contamination estimation condition

\begin{tabular}{ll}
\hline \multicolumn{1}{c}{ Parameter } & \multicolumn{1}{c}{ Source } \\
\hline Reactor coolant mass and density & Plant design data \\
Wetted surface area & Plant design data \\
CVCS purification factor & Plant design data \\
Deposition/erosion coefficient & Calculated by Beal's theory \\
Particulate fraction of nuclide & Measured and estimated data \\
Release rate of CP from the core & Erosion factor at reactor core \\
Escape rate of FP by the fuel defect & WAPD-TM-29 [9] \\
Release rate of FP from fuel surface & Derived from erosion factor \\
FP/CP ratio & Measured data \\
\hline
\end{tabular}




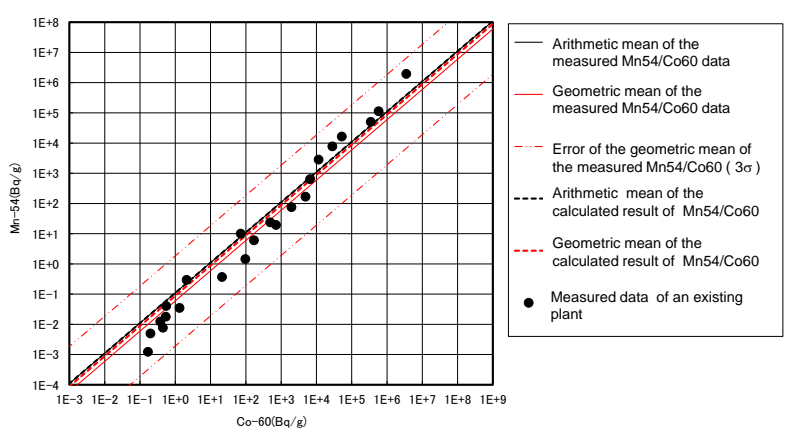

Figure 4. Calculation result of Mn-54/Co-60

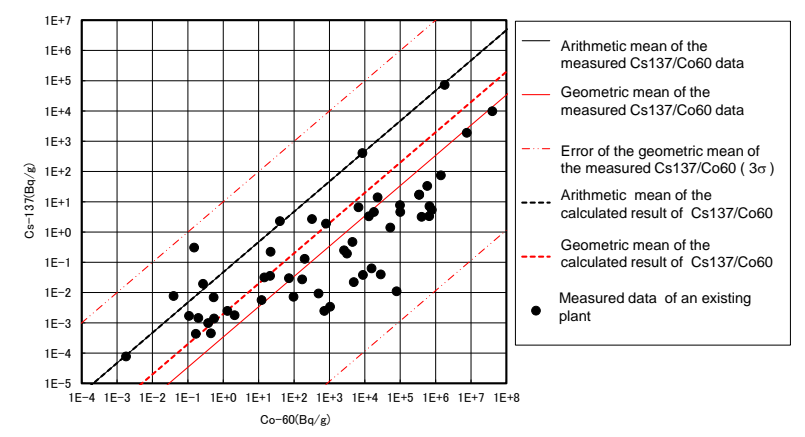

Figure 5. Calculation results of Cs-137/Co-60

\section{Nuclides screening for the clearance}

Nuclides screening for the clearance is carried out based on the contamination calculation results of regulated 33 nuclides in Japan. Nuclides screening method is in compliance with Atomic Energy Society of Japan standard [10]. Table 3 shows nuclides screening result. 10 nuclides, so-called "major nuclides" such as Co-60 and Cs-137 etc., are identified.

There is no variation of the calculated results because input parameters are nominal value of the plant design data because it is difficult to determine variation of all plant design data, and thus variation of measured data is introduced in the screening of the nuclides for the clearance. In this screening, only measured variation of FPs is considered because measured CPs data (e.g. Mn-54) have small variation compared to measured FPs data (e.g. Cs-137). FPs variation is introduced by multiplying concentrations of FPs by 0.001 to 100000 . Figure 6 shows the result of nuclides screening with measured variation. Vertical axis is the summation of concentrations divided by clearance level ( $\Sigma \mathrm{D} / \mathrm{C})$ and thick line is the criterion value for nuclides screening. The result is that nuclides to be considered obtained by screening with the variation are the same as that without the variation. This is because Co-60 is the dominant nuclide of 33 nuclides and Cs-137, the most dominant nuclide of FPs, is two digits lower than the Co-60 concentration. Even if FP concentration has some fluctuates, no influence is to be given on the nuclide screening.

\section{Conclusion}

Contamination estimation method for PWR has been developed. This method uses both design and measured data and can estimate RCS, CVCS, RHRS, SFPCS and other components. Contamination calculation results are consistent with measured data. In order to apply this method to the contamination estimation for the PWR operational waste and for plant decommissioning waste, the alpha-nuclides/Co-60 data and measured contamination data will be required.

Table 3. Nuclide screening result for the clearance

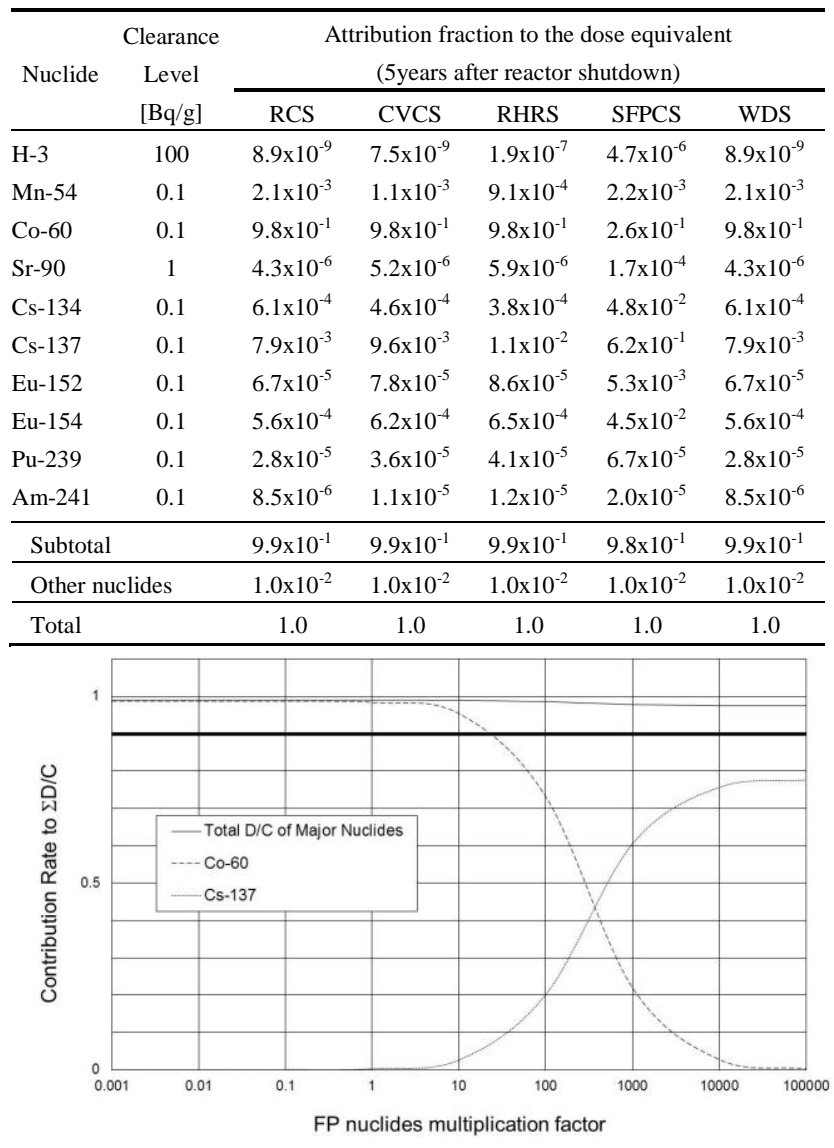

Figure 6. Nuclide screening with measurement variation

\section{Acknowledgements}

The authors wish to thank Mr. Kuroda and Mr. Saigusa for the helpful comments to prepare this paper.

\section{References}

[1] W.A. Rhoades and R.L. Childs, The DORT Two-dimensional Discrete Ordinates Transport Code System, RSIC-CCC-484, Oak Ridge National Laboratory, (1989).

[2] A.G. Croff, ORIGEN2-A Revised and Updated Version of the Oak Ridge Isotope Generation and 
Depletion Code, ORNL-5621, Oak Ridge National Laboratory, (1980).

[3] T. Nishimura and K. Kasahara, Improvement of Crud Behavior Evaluation Code (ACE), Proc. 1998 JAIF Int. Conf. on Water Chemistry in Nuclear Power Plants, Kashiwazaki, Japan, Oct. 13-16, 1998, (1998), pp.310-314.

[4] S.K. Beal, Deposition of Particles in Turbulent Flow on Channel or Pipe Walls, Nucl. Sci. Eng. 40 (1970), pp. 1-11.

[5] S.K. Beal, The Effect of Erosion and Deposition on Sampling of Entrained Particles, WAPD-TM-1014, Bettis Atomic Power Laboratory, (1972).

[6] Y. Sakamoto and S. Tanaka, QAD-CGGP2 and G33-GP: Revised Version of QAD-CGGP and G33-GP, JAERI-M 90-110, Japan Atomic Energy Research Institute, (1990).

[7] A.G. Croff, M.A. Bjerke, G.W. Morrison and L.M.
Petrie, Revised Uranium-plutonium Cycle PWR and BWR Models for the ORIGEN Computer Code, ORNL/TM-6051, Oak Ridge National Laboratory, (1978).

[8] Nuclear Standard Committee of Japan Electric Association, Quality Control Guide for Nuclear Fuels Used in Nuclear Power Plants, JEAG4204-2009, Japan Electric Association, (2009). [in Japanese]

[9] P.W. Frank, K.H. Vogel and P. Cohen, Radiochemistry of Third PWR Fuel Material Test X-1 Loop NRX Reactor, WAPD-TM-29, U. S. Atomic Energy Commission, (1957).

[10]Atomic Energy Society of Japan standard, Monitoring for Clearance with Clearance Level, AESJ-SC-F005: 2005, Atomic Energy Society of Japan, (2005). [in Japanese] 